\title{
David El Kenz, Les usages subversifs du martyre dans la France des troubles de religion: de la parole au geste
}

\section{Filippo Fonio}

\section{(2) OpenEdition}

1 Journals

\section{Edizione digitale}

URL: https://journals.openedition.org/studifrancesi/40536

DOI: 10.4000/studifrancesi.40536

ISSN: 2421-5856

\section{Editore}

Rosenberg \& Sellier

\section{Edizione cartacea}

Data di pubblicazione: 1 juillet 2004

Paginazione: 176

ISSN: 0039-2944

\section{Notizia bibliografica digitale}

Filippo Fonio, «David El Kenz, Les usages subversifs du martyre dans la France des troubles de religion: de la parole au geste», Studi Francesi [Online], 142 (XLVIII | I) | 2004, online dal 30 novembre 2015, consultato il 09 septembre 2021. URL: http://journals.openedition.org/studifrancesi/40536; DOI: https://doi.org/10.4000/studifrancesi.40536

Questo documento è stato generato automaticamente il 9 septembre 2021.

\section{(c) $(1) \odot$}

Studi Francesi è distribuita con Licenza Creative Commons Attribuzione - Non commerciale - Non opere derivate 4.0 Internazionale. 


\title{
David El Kenz, Les usages subversifs du martyre dans la France des troubles de religion: de la parole au geste
}

\author{
Filippo Fonio
}

\section{NOTIZIA}

DAVID EL KENZ, Les usages subversifs du martyre dans la France des troubles de religion: de la parole au geste, in FRANK LESTRINGANT, PIERRE-FRANÇOIS MOREAU, Martyrs et martyrologes, «Revue des Sciences Humaines», 269, I, 2003, pp. 33-51.

1 «Cette étude retient deux types d'apologies. En premier lieu, des histoires individuelles de protestants suppliciés rassemblées, mises en forme et réécrites dans des séries de volumes épousant le modèle de l'Histoire ecclésiastique d'Eusèbe de Césarée. En second lieu, à partir de l'exemple du régicide de Jacques Clément, des récits catholiques épars, publiés au lendemain d'un événement unique, suivant la forme de l'occasionnel et du pamphlet» (p. 34). A partire dall'individuazione delle due tipologie, lo studioso traccia due profili distinti, tuttavia non privi di punti di contatto: quello del martire cattolico e quello del martire protestante, individuando nel contempo i caratteri dell'uso strumentale del martirio da parte cattolico-romana, e da parte ugonotta. La letteratura apologetica protestante, ad esempio l'Histoire des Martyrs, raccolta iniziata da Jean Crespin e ultimata da Simon Goulart, considera alla stregua di martiri coloro i quali furono arsi sul rogo per crimini di natura confessionale nel periodo delle guerre di religione. Campione della fede nell'ottica degli apologeti cattolici è invece il domenicano regicida Jacques Clément, la cui figura domina la letteratura cattolica alla chiusa del XVI secolo. L'agiografia ugonotta risulta maggiormente incentrata sugli aspetti giudiziari, in cerca appunto di una legittimazione delle azioni dei condannati, mentre quella cattolica teorizza in maniera più esplicita la liceità della ribellione all'autorità regia, fino alla giustificazione della monarcomachia con profusione di esempi veterotestamentari. Le due posizioni sono tuttavia assai vicine, in quanto 
entrambe partono dal presupposto di una subordinazione dell'ordine terrestre a quello divino. L'analisi dei testi proposta dall'autore, nonché le considerazioni sull'evolversi della situazione politica e sociale dalle prime guerre di religione alla fine del secolo, mette in luce inoltre il carattere piuttosto verbale e teorico della strumentalizzazione ugonotta del martirio, ivi comprese le professioni di fede riformata e i salmi che si vorrebbero recitati dai martiri sul rogo. Anche la componente metaforica si trova al centro dell'apologetica protestante, ad esempio nell'episodio dello scempio del cuore di François II, regicidio metonimico, o nei moti iconoclasti di Orléans. La propaganda cattolica è invece legata alla pratica della resistenza, al culto dell'uomo d'azione e dell'eletto, fino a giungere alle soglie di una mistica dell'atto sovversivo. Mentre l'apologia dei martiri ugonotti tende infine a perdere importanza nella seconda metà del secolo, per un progressivo politicizzarsi del conflitto, all'epoca l'icona della propaganda cattolica è ancora di là da venire. 